\title{
Negotiating Educated Subjectivity: Intern Labour and Higher Education in Hong Kong
}

\author{
Lingnan University, Hong Kong, chong@ln.edu.hk
}

\begin{abstract}
This article examines interns' negotiation of their work identity, with a focus on the nexus of transformations in higher education and the "new" capitalist economy. The existing literature on internships emphasizes the restructuring of employment in creative and cultural industries, the surplus cultural labour supply, and the impact of internships on the career paths of educated youth mostly in western countries. Based on interviews and participant observation in Hong Kong, I argue that the intern's "educated subjectivity", nurtured by new values and practices of higher education such as selfreflexive learning and interfacing with community, plays an important role in the making of the intern economy. These values and practices contribute to the ambiguity and elasticity of the role of interns identified in previous research on internships.
\end{abstract}

Keywords: internships, cultural work, higher education

Acknowledgement: The author thanks the special issue editors and the anonymous reviewers for their helpful comments and suggestions.

Since 2001, my colleagues and I have taught a summer internship course, which was set up by the Department of Cultural Studies of Lingnan University in conjunction with partner institutions in three areas: media, performing arts groups, and community organizations. Over the past four years, the course has been an elective credit in the Bachelor of Arts program. ${ }^{1}$ According to course evaluations, most students appreciate this course and are satisfied with what they learn from their internship. However, I eventually discovered that few of the students enter full-time employment in the areas of the internship program upon graduation. This outcome does not seem to be tied to the availability of jobs; in fact, some of the participants were not eager to find employment in the areas in which the interned. In light of this, I was increasingly puzzled as to why students reported that their unpaid internships were significant and valuable to them.

Despite the lack of official figures on student interns, internship schemes, and their contribution to Hong Kong's economy, the number of schemes and placements is growing. For instance, the number of participants in internship programs offered by Lingnan University has climbed from 185 in 2011 to 295 in 2014, growing an average of 17.4 percent per year. ${ }^{2}$ While the Hong Kong government affirms universities' effort to extend internship programs, the "employability" agenda does not loom large over educational concerns. The primary reason is that Hong Kong's job market looks healthier than that of most advanced economies (Government of the Hong Kong Special Administrative Region 2012, 83). In the second quarter of 2014, the youth unemployment rate for the 25-29 age group and university graduates was merely 3.5 percent and 2.7 percent respectively, which is close to Hong Kong's overall unemployment rate (Government of the Hong Kong Special Administrative Region 2014, 73).

But low unemployment does not mean that life is easy for university students and graduates, who are expected to work long hours for a meager income, pay off student loans, and save enough money to purchase a tiny flat in an extremely expensive property market (The Hong Kong Federation of Youth Groups 2013). According to a survey by Randstad (2014, 13-14), local workers suffer from extended working hours and stressful work environments,

\footnotetext{
${ }^{1}$ Some partner institutions offer a stipend ranging from $\mathrm{HK} \$ 2,000-\mathrm{HK} \$ 5,000$. Students whose host organizations do not offer a stipend are entitled to a subsidy of HK\$2,000 provided by the department.

${ }^{2}$ This information is provided by the Student Services Centre of Lingnan University. These figures do not include the programs run by departments that did not report to the Centre.
} 
and their job satisfaction is almost the lowest in the world. Although Hong Kong has almost full employment, many young people feel pessimistic about securing a bright future for themselves.

This article explores how interns negotiate their work identity, with a focus on the nexus of transformations in higher education and the "new" capitalist economy. While existing literature on internships emphasizes the restructuring of employment in creative and cultural industries, the surplus cultural labour supply, and the impact of internships on the career paths of educated youth mostly in western countries (Frenette 2013; Hesmondhalgh 2010; Overell 2010), my case study sheds light on the relationship between higher education and student interns' labouring experience. Theorizing universities' involvement in the development of intern labour is crucial to understanding the expansion of internships in non-professional fields.

\section{Intern Labour: Working or Learning?}

Critics of internships often see the proliferation of unpaid or low-paid internships as a consequence of a deterioration of industrial relations or the rise of creative industries. For example, critical accounts of internships are attentive to cultural workers' irregular employment patterns and insecure conditions and global socio-economic inequality (International Labor Organization 2004; Neff and Arata 2007; Pun and Chan 2012, 391-392). The rising numbers of interns are seen as newcomers in the army of precarious labour (Standing 2011; Perlin 2012), and the prevalence of internships can also be linked to the policies of various neoliberal regimes such as New Labour in the U.K., whose policy initiatives promoted creative industries and small business as solutions to economic problems (Oakley 2011).

In the critical literature on internships, some scholars draw attention to work culture, in particular, the new values and practices of the creative industries. For instance, David Hesmondhalgh and Sarah Baker $(2011,145-146)$ notice in their study of creative industries that unpaid internships and poorly paid freelancing are often naturalized as the first step of self-realization and necessary for entry into these industries. Instead of focusing on the requirement of an internship for entering professions in creative industries, Alexandre Frenette $(2013,372)$ looks at the "ambiguous" nature of intern labour, such as its temporary basis, the flexibility of the work role, and the emphasis on adaptable skills, which appeals to aspiring interns. On the one hand, companies may find it difficult to formalize internship programs, and cater to interns whose backgrounds, interests, and commitments are diverse. Companies may leave space for interns to pick up tasks, ranging from mundane, administrative duties to professional responsibilities, according to the interns' abilities and preferences and the organization's immediate needs. On the other hand, the lack of well-defined objectives or tasks in the use of intern labour can attract young people with different motivations and little working experience to join internship programs.

The ambiguity of the internship, implicitly defined against the relative clarity of a traditional employment relationship, is usually assumed to be consistent with the unstable and unpredictable conditions of creative industries and their organizational cultures (Frenette 2013, 368). However, the role played by the higher education sector in shaping the "ambiguity" of intern labour needs closer examination. There is a growing literature on work-based learning and higher education, which variously confirms the benefits of internships to students and educators (Swail and Kampits 2004), develops effective models for aligning education paths with career plans (Howard 2004), or identifies the conditions for critical pedagogy (Breunig 2005; Lester and Costley 2010; Berger, Wardle and Zezulkova 2013). Some scholars evaluate the employability agenda of higher education and its impact on professional practices and identities (Thornham and O'Sullivan 2004; Willis 2010). Further study is needed to understand the uniqueness of student interns' working-learning experience, which is located at the intersection of labour and educational practices. As most interns are students or recent graduates, the nuance and complexity of their roles as learners and their relationship with pedagogical practices and workplace conditions deserve scrutiny. Interns often shift between the role of worker and learner, especially in a well-designed program. While interns perform their daily work, they continually examine their own thoughts, motivations, feelings, and behaviours, and ask why more than how. My study attempts to address the subjective experi- 
ence of student interns by exploring some of the ways they negotiate their identities at the intersections of a professional field and an education institution.

\section{Data, Method, and Background}

Data presented in this article are drawn mainly from my participant-observation as an instructor of an internship course since 2010 and semi-structured interviews in 2014 with 10 young graduates (three men and seven women). ${ }^{3}$ Interviewees were selected from the 110 people who participated in the internship course since 2010. The sample consists of respondents who had worked in the three fields associated with the internship program: media, performing arts, and community organizations. Interviewees were asked 53 questions regarding their initial expectations for their internship, the process of selecting an organization and securing their position, first impressions, pleasures, and frustrations in the placement, and their assessments and memories. The interviews also addressed the relevance of the internship to the participants' studies, career aspirations, and current jobs. In addition to former interns, I interviewed two internship course instructors about the program's institutional history, their teaching philosophy, pedagogical practices, and course design.

The internship course is intended to encourage students majoring in Cultural Studies to put theory into practice, to gain better knowledge of the nature and skills of "cultural work", and to develop a professional ethos to prepare them for their career (Department of Cultural Studies, Lingnan University 2013). The course is characteristic of the curriculum design of the B.A. (Hons.) in Cultural Studies at Lingnan University, the first undergraduate program of its kind in Chinese-speaking societies. The central idea of the degree's curriculum structure, according to its initiator and designer, Ching-kiu Chan, is "strategic border re-alignment" (Chan 2002, 231). That is, it has a trans-disciplinary orientation that not only consists of bringing multiple disciplines together, but also highlighting the social and cultural contexts of Hong Kong and China, and emphasizing local issues.

Most faculty members in the department were attracted to Cultural Studies because they were previously frustrated by disciplinary constraints. Being liberated from conventional disciplines informs the curricular design of the B.A., which has a vision of a field of study and engagement beyond established disciplines and professions. As the external examiner of the program, Graeme Turner, notes, the Lingnan students-non-elite students with low economic and cultural capital-are encouraged to facilitate intellectual and practical dialogues between cultural studies concepts and their own social engagement, rather than read theoretical canons (Turner 2012, 87). The areas covered by the internship course are not limited to a specific professional field or definition of "cultural work", but, rather, are developed from the socio-cultural concerns of the faculty members of the department and their alignment with the themes of the required courses and two streams of study ("Social and Historical Studies" and "Literary and Media Studies"). While the internship is defined as an opportunity for interfacing with community, the partner institutions are mainly selected through instructors' personal networks and community involvement.

In what follows, I summarize respondents' common expectations and analyze how these expectations come about in their learning environment. Next, I attend to cases in which students report having both enriching and frustrating experiences, and articulate the patterns of their adaptation to their labour conditions. Finally, I foreground the process of "labouring to learn" and its relationship with tertiary education. I conclude by thinking through the significance of these experiences for the working life of educated youth in Hong Kong.

\footnotetext{
${ }^{3}$ Approximately half of the interviews were conducted by Chan Pui Ming.
} 


\begin{tabular}{|l|l|l|l|}
\hline Name $^{4}$ & Sex & Age & Host Organization \\
\hline Josephine & F & 25 & Media \\
\hline Kelvin & M & 29 & NGO \\
\hline Eva & F & 24 & Performing Arts Group \\
\hline Fiona & F & 23 & NGO \\
\hline Patrick & M & 26 & Media \& Arts \\
\hline Erica & F & 25 & Performing Arts Group \\
\hline Holden & M & 24 & Media \& Arts \\
\hline Emily & F & 24 & Media \\
\hline Sussie & F & 23 & NGO \\
\hline Pinky & F & 23 & Media \\
\hline
\end{tabular}

Table 1: List of anonymized interviewees

\section{Findings}

\subsection{Expectations}

While internship experiences vary, students' initial expectations for their internships are similar. For example, the interns in this study are not necessarily aspiring for a career, even though instructors emphasize the benefits of getting a foot into industries and expanding social networks. All but one intern admitted that earning academic credits within two months-a period shorter than an academic semester-is the most immediate reward of the internship course. This seems to be a stronger incentive to participate than acquiring professional skills and building up personal networks for a future career. Instead of thinking seriously about career planning, students usually chose host companies that they found to be interesting and challenging.

There are also cases of participants seizing an internship as a chance to do something radically different from their way of life and personalities. Josephine, for example, had concentrated on her studies but rarely participated in class discussions and extra-curricular activities. Nor was she eager to engage in social and political debates. So, I was somewhat surprised by her decision to intern as a reporter for an independent media outlet. She expected a special experience: "I wanted to try it and see if it was suitable for me. I wondered if I am qualified for a job related to public affairs." Despite Fiona's religious beliefs and her family's moral conservatism, she learned about gay and lesbian issues and pro-sex feminist theories in Cultural Studies and was puzzled by local debates on sexual discrimination, pornography, and the legal recognition of same-sex marriage in recent years. Unsure about her standpoint, Fiona chose to work with a queer community group, which she saw an opportunity to learn more about sexual rights issues. Fiona's ambiguous role as an intern, neither an advocate nor a staff member, allowed her to engage in advocacy, yet without an obligation to identify with the activists' causes: "After graduation, given my religious background, I probably would not have any chance to think about the controversies on sex and religion, especially listening to sexual minorities' views."

Josephine and Fiona assumed that their placements would allow them to depart from mainstream work and life-though, sometimes, the nature of an internship is not significantly different from regular office work. According to my interviews and observation, students saw their internship as a learning process extending beyond the classroom. Filing, making cold calls, entering information into databases, sitting idly, or nervously attempting to have conversations with busy staff-most students worked patiently and diligently. Although some organizations expected them to be the next generation of employees, the interns primarily saw themselves as learners and their work as taking on new challenges and gaining exposure to the real world outside the ivory tower and their normal life.

\footnotetext{
${ }^{4}$ Pseudonyms are used for the research participants.
} 


\subsection{Exploitation and Pleasure}

More than half of the interns in my study described their working experiences as exploitative in one way or another, yet they expressed this idea without a strong sense of injustice. Apart from concerns about unpaid or underpaid labour, some interns lamented their mundane tasks and their status as disposable labour. Eva, who interned with a performing arts group as a customer service worker answering phone calls, occasionally prepared Chinese herbal medicine for her director. Kelvin and Patrick, who interned in a small documentary company, were assigned to mail delivery. They were sometimes drowned in tedious tasks without a clear understanding of the job or the mission of the organization. Patrick, grumbling about his supervisor's paternalism, re-defined the role of the intern as "assistant": "Interns are supposed to learn, but I can only assist [the host organizations]." Eva invoked the idea of flexibility: "You can't ask why you have to do this or that. The scale of the company is so small. The staff and director always emphasize flexibility and my job [...] is by nature ambiguous."

According to the interns in this study, what matters most to their feeling of being exploited is not unpaid labor or heavy duties. Instead, their working conditions and experience could be summarized by Richard Sennett's notion of the three social deficits of the "new capitalism": low institutional loyalty, lack of informal trust among workers, and weakening of institutional knowledge (Sennett 2006, 63-72). On the one hand, students do not receive professional training related to the sectors of their host companies; on the other, most companies fail to offer formalized programs such as orientation sessions, formal training, systematic instruction, and sufficient guidance. Interns have to familiarize themselves with the working environment from scratch.

However, the ambiguity inherent in the intern's role, which largely defines their working conditions, can also be a source of pleasure. Erica enjoyed her work much more when she shifted to the role of an audience member. She was invited by her supervisor to attend the show run by the company with which she interned and to share her opinion and suggestions for improvement, because the director wanted to make his production more appealing to young people. What affects job satisfaction is not simply the nature of the tasks, however. What matters most is whether and to what extent interns can articulate the meanings of their roles and work for themselves. While Patrick bemoaned the fact that his supervisor treated him as a teenage student, subject to paternalistic discipline and surveillance, Holden, who worked as an intern with Patrick, enjoyed multi-tasking very much: "It is really interesting. We had so many different tasks. As soon as you learned one, you are assigned to another one. I have a lot of eye-opening experiences." What made Holden happy about his internship was the opportunity to learn how to run a small arts group and it helped him think about his longterm career plan. Kelvin worked for a community group raising public awareness about the detrimental impact of redevelopment projects on local neighborhoods. Despite performing fragmented tasks, Kelvin shared the mission of the group and appreciated his internship as eye-opening and consciousness-building. Both Holden and Kelvin viewed their hardships as necessary for gaining special learning experience.

\subsection{Labouring to Learn}

Researchers have noted the disparity between interns' expectations and the knowledge interns develop or the networks they build through their placements (Frenette 2013; Tayler and de Laat 2013; Figiel 2013). What interests me is how interns negotiate his gap. Despite occasional complaints about their working conditions and skill cultivation, none of the students interviewed for this study felt that there was nothing received in return for the labour they provided to the organization for which they interned. Students were inclined toward compliance in the hopes that they would acquire skills, maintain good relationships with colleagues, and keenly observe the organizations where they interned. Some felt disappointed but nonetheless submerged their critiques. Rather than leading to conflict, debate, and re-evaluation in host organizations, the interns' frustration, disillusionment, or perplexity were taken up as topics in the reflexive essays submitted to instructors and shared informally among peers. Interestingly, all the students in this study characterized their internship as a kind of "enlight- 
enment" and highly recommended others to take the course, because they found it invaluable for reflecting upon their background knowledge, social roles, and career planning. Here, reflection is not simply a component of assessments such as a writing journal and a reflective essay. It is also about interns' self-development, career preparation, and life planning, which are essential for their compliance with unpaid internships and their feeling of being "enlightened".

While all participants agreed that their internship was educational, almost no one found Cultural Studies theories and concepts to be useful in the workplace. Internships do, however, become a lens through which students come to understand and reflect on a variety of academic issues and concepts. The daily work they performed and observed in internships, regardless of whether their experience was positive or negative, was introduced as a concrete example in their coursework and becomes the subject of their reflexive essay. For instance, most students said that they finally understood the meaning of "cultural institution" and "culture industry" after their internship, and reflected upon these ideas in their assignments for the internship course.

What the students learn from their internships is not confined to academic knowledge, however. Josephine's experience as an intern reporter turned out to be disappointing. She attributed this to a lack of supervision, her poor knowledge of political issues, and passive personality. Yet Josephine still saw the internship as a good learning experience: "If you go to work, you can only learn how to accomplish particular tasks, but the internship allows me to think more." What she meant by "think more" is not only academic, but also in the sense of thinking about her future. After the internship, she gave up her dream to be a journalist and gave serious thought to other careers. Kelvin, who worked for a group advocating community involvement in an urban redevelopment project, characterized his internship as bringing new perspectives on his life course: "How could I imagine myself standing on the street, delivering leaflets or talking to the passersby about things happening in our society? If I didn't [take an] internship, I would never do this [policy advocacy] by myself." Despite currently working as an office worker rather than a campaigner, Kelvin believes that he is no longer politically apathetic, as he was before he took the internship. And Holden decided to work in a large and more bureaucratic organization rather than a small group like his host organization after his internship. He expected to learn more about the operation of media or arts organizations by working in a more institutionalized environment. Interning with a small organization gave him a lot of freedom and flexibility, yet insufficient guidance and formal training. Now Holden works as a full-time editor for one of the biggest newspapers in Hong Kong.

Emily interned at a commercial radio station for more than 12 hours every day and regularly shifted roles between production assistant, reporter, and program host. After her internship, Emily initially abandoned media as her dream field because she believed that such a heavy workload would ruin her life. However, after a few months, she changed her mind and looked for a media job: "Commercial radio gives me something more than particular skills-[it gives me] news sense. It is difficult to describe what it is. It is a mode of thinking and an ability to present information from a sharp angle. For example, I never knew what a sound bite was until I worked at that company." She decided to follow her passion for media, but attempted to strike a balance between work and life. After their internships, most of the students, like the cases above, do not end up working in the particular industries of their hosts. But the students do feel more eager to clarify their career plans and to pursue meanings in work and life.

\section{Conclusion}

While the instructors leading the internship course repeatedly highlight the significance of "practices" in Cultural Studies, most student interns position themselves as learner rather than practitioner. For these students, internships are less about gaining transferable skills in exchange for unpaid labour or engaging themselves in community organizations and cultural work. Instead, internships involve a process of "active searching", in which students try, challenge, and rework ideas they learn in the classroom, and enhance the capacity to think about 
the fields with which students are not acquainted. What concerns them is their ability to be reflective about themselves and their surroundings. Disappointing work experience does not deter interns from "labouring to learn". Finding comfort in discomfort, they appreciate Cultural Studies for equipping them with knowledge, intellectual tools, and guidance to build critical accounts of their work, the organization where they interned, and themselves.

Interns, as Judith Tayler and Kim de Laat note, replace their "work selves" with "internship selves", attributing unpleasant experiences to a lack of supervision, unfriendly co-workers, or bad luck, rather than being critical of unpaid internships as exploitative $(2013,93)$. My smallscale study suggests that interning is a process of negotiation over subjectivity, engendering a high-level learning that enables students to play the role of self-directed learners. Student interns, with their ambiguous roles, could keep psychological distance from depressing workplaces or tedious tasks. They perceive their role as that of a learner looking for new experiences and reflecting upon their work, and thereby find the unpaid or low-paid labour bearable. In this light, internships stand as an example of "knowledge capitalism", or university reform in the period of neoliberal restructuring, whereby learning and working are becoming blurred to the extent that capitalist power relations are obscured by the discourse and practice of experiential learning (Burton-Jones 1999; Marginson and Considine 2000; Olssen and Peters 2005).

Interns, rather than being trained as followers of procedures and rules, are encouraged to develop themselves as an "educated subject" who voluntarily adjusts "the innermost aspects of the self" to comply with a changing institutional environment (Fendler 2001). This is the reason why the participants in this study view their internships as a sort of "enlightenment." The substance to be educated in an internship is, I argue, not necessarily intellectual ability, specific skills, and behavioural discipline. Instead, the key is to develop a self-enabling subject, one who is embodied with a temperament, a motivation, and a desire to take on various challenges, which are perceived as highly beneficial experiences, adventures in learning, or, even, a blessing.

\section{References}

Berger, Richard, Jonathan Wardle and Marketa Zezulkova. 2013. No Longer Just Making the Tea: Media Work Placements and Work-Based Learning in Higher Education. In Cultural Work and Higher Education, edited by Daniel Ashton and Caitriona Noonan, 87-109. Hampshire: Palgrave Macmillan.

Breunig, Mary. 2005. Turning Experiential Education and Critical Pedagogy Theory into Praxis. Journal of Experiential Education 28 (2): 106-122.

Burton-Jones, Alan. 1999. Knowledge Capitalism: Business, Work, and Learning in the New Economy. Oxford: Oxford University Press.

Chan, Ching-kiu. 2002. Building Cultural Studies for Postcolonial Hong Kong: Aspects of the Postmodern Ruins in between Disciplines. Cultural Studies: Interdisciplinarity and Translation 20: 217237.

Department of Cultural Studies, Lingnan University. 2013. Internship Course (CUS 299): Student Handbook. Accessed June 10, 2015. http://www.In.edu.hk/cultural/students/internship/2013/Internship course Student Handbook 2013.pdf.

Fendler, Lynn. 2001. Educating Flexible Souls: The Construction of Subjectivity through Developmentality and Interaction. In Governing the Child in the New Millennium, edited by Kenneth Hultqvist and Gunilla Dahlberg, 119-142. London: Routledge.

Figiel, Joanna. 2013. Work Experience Without Qualities? A Documentary and Critical Account of an Internship. ephemera: Theory \& Politics in Organization 13 (1): 33-52.

Frenette, Alexandre. 2013. Making the Intern Economy: Role and Career Challenges of the Music Industry Intern. Work and Occupations 40 (4): 364-397.

Government of the Hong Kong Special Administrative Region. 2012. Third Quarter Economic Report 2012. Hong Kong: Hong Kong SAR Government.

Government of the Hong Kong Special Administrative Region. 2014. Half-yearly Economic Report 2014. Hong Kong: Hong Kong SAR Government. 
Hesmondhalgh, David. 2010. User-generated Content, Free Labour, and the Cultural Industries. ephemera: Theory \& Politics in Organization 10 (3/4): 267-284.

Hesmondhalgh, David and Sarah Baker. 2011. Creative Labour: Media Work in Three Cultural Industries. New York and London: Routledge.

Howard, Adam. 2004. Cooperative Education and Internships at the Threshold of the Twenty-First Century. In Handbook for Research in Cooperative Education and Internships, edited by Patricia L. Linn, Adam Howard and Eric Miller, 3-10. Mahwah, NJ: Lawrence Erlbaum Associates.

International Labor Organization. 2004. Economic Security for a Better World. Geneva: ILO.

Lester, Stan and Carol Costley. 2010. Work-based Learning at Higher Education Level: Value, Practice, and Critique. Studies in Higher Education 35 (5): 561-575.

Marginson, Simon and Mark Considine. 2000. The Enterprise University: Governance, Strategy, Reinvention. Melbourne: Cambridge University Press.

Neff, Gina and Giovanni Arata. 2007. The Competitive Privilege of Working for Free: Rethinking the Roles that Interns Play in Communication Industries. Paper presented at the meeting of American Sociological Association, New York City, August 11.

Oakley, Kate. 2011. In its Own Image: New Labour and the Cultural Workforce. Cultural Trends 20 (34): 281-289.

Olssen, Mark and Michael A. Peters. 2005. Neoliberalism, Higher Education, and the Knowledge Economy: From the Free Market to Knowledge Capitalism. Journal of Education Policy 20 (3): 313-345.

Overell, Stephen. 2010. The Role of Internships. In Disconnected: Social Mobility and the Creative Industries, edited by Ryan Shorthouse, 80-89. London: Social Market Foundation.

Perlin, Ross. 2012. Intern Nation: How to Earn Nothing and Learn Little in the Brave New Economy. London: Verso.

Pun, Ngai and Jenny Chan. 2012. Global Capital, the State, and Chinese Workers: The Foxconn Experience. Modern China 38 (4): 383-410.

Randstad. 2014. Randstad World of Work Report: The Talent Strategy Game-changer Series. Accessed September 26, 2014. http://www.randstad.cn/FileLoad/Attachment/20140224141329449.pdf.

Sennett, Richard. 2006. The Culture of the New Capitalism. New Haven and London: Yale University Press.

Standing, Guy. 2011. The Precariat: The New Dangerous Class. New York: Bloomsbury Academic.

Swail, Watson Scott and Eva Kampits. 2004. Work-based Learning \& Higher Education: A Research Perspective. Washington, DC: Educational Policy Institute.

Tayler, Judith and Kim de Laat. 2013. Feminist Internships and the Depression of Political Imaginations for Women Studies. Feminist Formations 25 (1): 84-110.

The Hong Kong Federation of Youth Groups. 2013. The Daily Needs and Financial Pressures of Young People with Government Loans. Hong Kong: HKFYG.

Thornham, Sue and Tim O'Sullivan. 2004. Chasing the Real: "Employability" and the Media Studies Curriculum. Media, Culture \& Society 33 (2): 289-298.

Turner, Graeme. 2012. What's Become of Cultural Studies? Los Angeles: SAGE.

Willis, Jenny. 2010. How do Students in the Creative Arts Become Creative Professionals? In Learning to be Professional through a Higher Education, edited by Norman Jackson. Accessed September 13, 2014. http://learningtobeprofessional.pbworks.com/f/JENNY+WILLIS+D4+FINAL.pdf.

\section{About the Author}

is an Assistant Professor of Cultural Studies at Lingnan University in Hong Kong. His research interests include urban studies, social movements, and neoliberalism in non-Western contexts. 